\title{
Concrete Slabs under a Combination of Loads in Shear
}

\author{
Eva O.L. LANTSOGHT \\ PhD Candidate \\ Delft University of \\ Technology \\ E.O.L.Lantsoght@tudelft.nl
}

Eva Lantsoght, born 1985, received her civil engineering degree from Vrije Universiteit Brussel in 2008 and M.S. from the Georgia Institute of

Technology in 2009 before joining Delft University of Technology as a PhD Candidate studying shear in concrete slabs.

\author{
Cor VAN DER VEEN \\ Associate Professor \\ Delft University of \\ Technology \\ C.vanderveen@tudelft.nl
}

Cor van der Veen received his civil engineering degree from Delft University of Technology in 1982 and PhD in 1990. At present he is associate professor in the research group of concrete structures.

\author{
Joost C. WALRAVEN \\ Full Professor \\ Delft University of \\ Technnology \\ J.C.Walraven@tudelft.nl
}

\begin{abstract}
Joost Walraven, born 1947 , received his civil engineering degree from Delft University of Technology in 1972 and his PhD degree in 1980. He is an Emeritus Professor of Concrete Structures of Delft University of Technology since 2012 .
\end{abstract}

\section{Summary}

Previous experimental research at Delft University of Technology indicated an increased shear capacity of slabs under concentrated loads as a function of decreasing distance to the adjacent line support. Expressions have been derived for this increase, including the definition of an appropriate effective width. However, it is unknown if the uniformly distributed loads on solid slab bridges, e.g. due to dead loads, that act over the full width can be combined with the effects of concentrated loads acting only over the associated effective width at the support. To study this problem, additional experiments have been carried out at Delft University of Technology, in which a combination of loads consisting of a concentrated load close to the support and a line load over the full slab width are applied. The experimental results prove that the superposition principle applies to combinations of concentrated loads and distributed loads.

Keywords: slab bridges; shear; experimental research; effective width; tests; reinforced concrete; live loads; superposition

\section{Introduction}

As a result of the increased traffic loads and intensity over the past decades, the live loads prescribed by the current codes such as the recently implemented EN 1991-2:2003 [1] result in higher shear stresses at the support. These shear stresses can be higher than the shear stresses for which existing structures are designed. At the same time, the requirements for shear in reinforced concrete as prescribed by EN 1992-1-1:2005 [2] are more conservative than the provisions from the former Dutch national code NEN 6720 [3]. These evolutions in the codes resulted in a number of existing bridges becoming shear-critical when assessed according to the governing codes. To better understand the behaviour of these structures in shear, an extensive research programme was started in the Netherlands. One of the aspects studied in this programme was the shear capacity of reinforced concrete slabs under concentrated loads. Most of the recent experimental research on slabs in shear studied the shear capacity of slabs under line loads [4,5]. These experiments showed that slabs under line loads in shear behave in a two-dimensional way and essentially as very wide beams. For slabs under concentrated loads, an increase in the shear capacity resulting from transverse load redistribution can be expected. This phenomenon wass studied in a first series of experiments carried out at Delft University of Technology. The results from the first series indicate an increased shear capacity in slabs under concentrated loads as compared to beams. The next step is to verify if the principle of superposition of concentrated and distributed loads is valid when an increased capacity is assumed for the concentrated loads.

\section{Slabs under concentrated loads in shear}

In the first series of experiments [6], a total of 18 slabs and 12 slab strips were tested under a concentrated load near the support. The aim of the first series of experiments was to quantify the influence of transverse load redistribution on the shear capacity of slabs under concentrated loads 
and, associated with this, to determine the effective width in shear that can be used. An enhancement factor of at least 1,25 for transverse redistribution is found [7] for loads close to the support, if compared to beams. This enhancement can be combined with the reduction factor for the contribution of loads near to the support in beams expressed by $\beta=a_{v} / 2,5 d_{l}$. The effective width can be determined based on a load spreading method that is used in French design practice: the load is distributed from the far side of the load towards the support under a $45^{\circ}$ angle.

The results also indicated that reinforced concrete slabs under a concentrated load behave essentially in a three-dimensional way, which is distinctly different from the two-dimensional shear carrying behaviour in beams [8]. The test results have indicated that the most important parameters influencing the shear capacity of slabs under concentrated loads close to the support are: the size of the loading plate, the distance between the load and the support and the overall width of the member. This indicates that the shear capacity of slabs under concentrated loads close to the support mainly depends on the geometrical properties, while surprisingly the influence of the concrete compressive strength is found to be insignificant for the studied mixtures.

\section{Hypothesis of superposition}

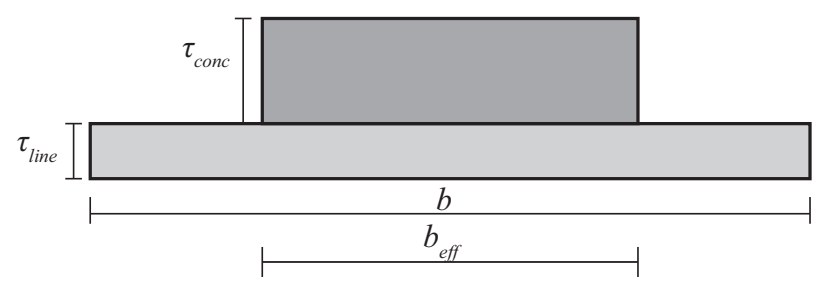

Fig. 1: Superposition of the shear stress due to a concentrated load over the effective width to the stress generated by a distributed load over the full slab width.
When a concentrated load on a slab is distributed over a certain effective width, $b_{\text {eff }}$, and thus a certain amount of transverse redistribution over the width of the slab is allowed, it is not known if this contribution of the concentrated load can be added to the contribution of the distributed load when assessing the shear capacity. The concept is sketched in Fig. 1. If the hypothesis of superposition is valid, then the sum of the shear stress due to the concentrated load over the effective width $\tau_{\text {conc }}$ and the shear stress due to the distributed load at failure over the full width $\tau_{\text {line }}$ should be at least equal to the ultimate shear stress in an experiment with a concentrated load only, $\tau_{t o t, c l}$. For the practice of the assessment of existing bridges, this principle can be applied to the occurring loads. If the hypothesis of superposition is valid, the wheel load can be distributed per axle over the effective width associated with this axle and combined with the contribution of the dead loads and lane load over the full width of the bridge.

In the literature and resulting slab shear database [9], no report is made of experiments on slabs under a combination of concentrated and distributed loads, except for experiments in which a small line load representing an edge load is applied at the tip of a cantilevering deck [10,11]. Therefore, the experiments on slabs in shear under a combination of loads are designed such that the shear stress at the support due to the line load corresponds with $50 \%$ of the shear stress at failure observed in the slab strips of $0,5 \mathrm{~m}$ wide under a concentrated load. The failure shear stress in the specimens with a small width is considered to be representative for the failure shear stress in a slab under a line load, as in both cases the shear is carried in a one-dimensional way. The resulting ratio of the contribution of the concentrated load and the uniformly distributed load to the shear stress at the support more closely resembles the ratio of contributions for the case of a slab bridge under dead load, superimposed loads and live loads.

\section{Experimental setup}

\subsection{Test setup}

A sketch of the top view of the test setup is presented in Fig. 2. The concentrated load can be moved along the width and span of the slab. The concentrated load is applied in a displacementcontrolled way by a hydraulic jack. A line load of $240 \mathrm{kN} / \mathrm{m}$ is applied at $1,2 \mathrm{~m}$ from the centre of the support at which the experiment is carried out. The line load is applied through an HEM 1000 beam loaded on top by a force-controlled hydraulic jack. In every experiment, the line load is applied as a preload, after which the concentrated load is increased until failure. The experiments 


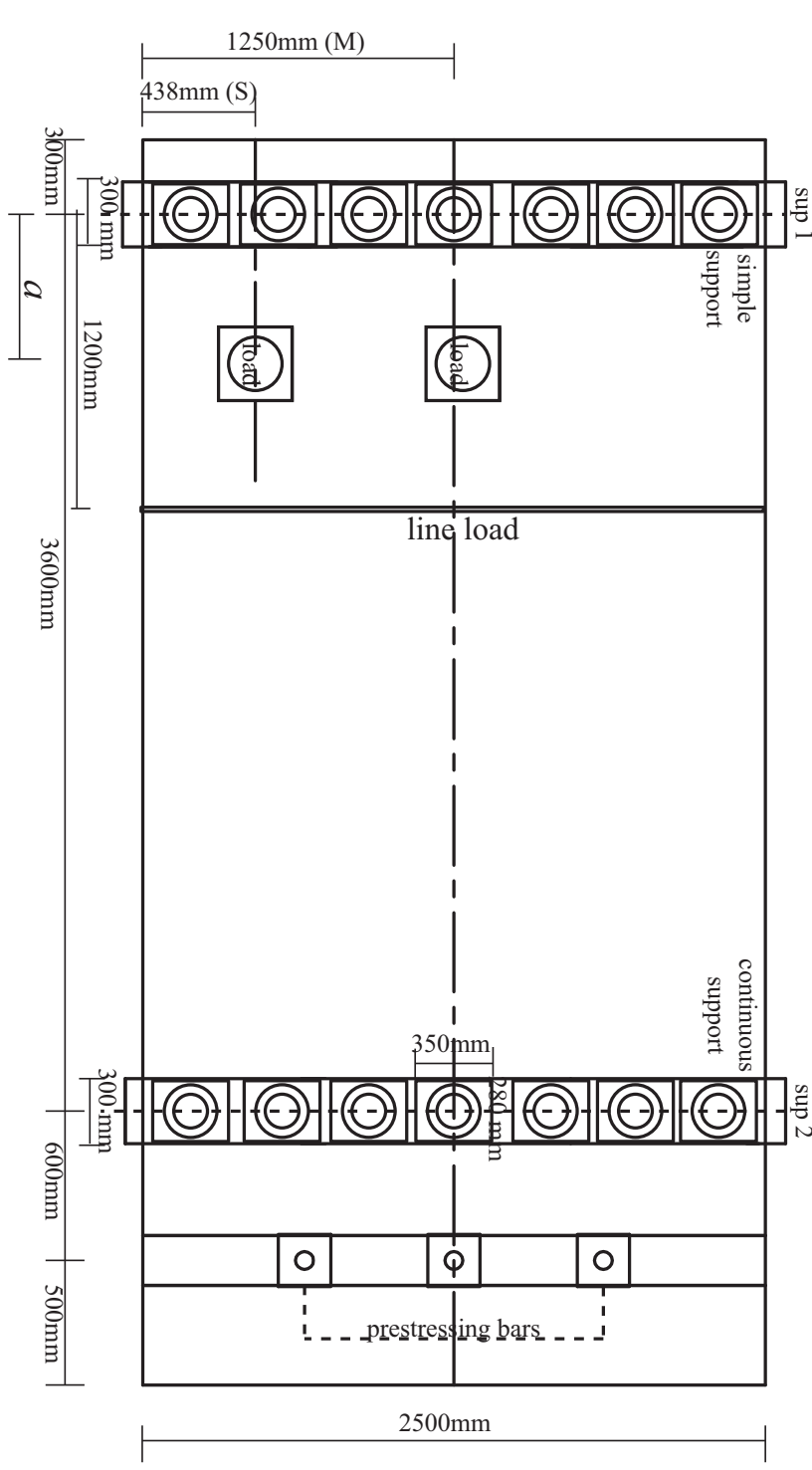

Fig. 2: Test setup for experiments on slabs under a concentrated load and a line load were carried out both close to support 1 (SS, sup 1 in Fig. 2) and support 2 (CS, sup 2 in Fig. 2). Loading plates of $200 \mathrm{~mm} \times 200 \mathrm{~mm}$ and $300 \mathrm{~mm} \times 300 \mathrm{~mm}$ were used. The supports were line supports and consisted of a steel beam (HEM 300) of 300mm wide, on which 7 bearings of $350 \mathrm{~mm} \times 280 \mathrm{~mm} \times 45$ $\mathrm{mm}$ equipped with load cells were placed. The bearings were either steel (S19-S22, S25, S26) or elastomeric (S23, S24) bearings. The elastomeric bearings contained 3 layers of $8 \mathrm{~mm}$ natural rubber, 4 layers of $4 \mathrm{~mm}$ steel S235 and 2 layers of 2,5 mm chloroprene, resulting in a compression stiffness of $2361 \mathrm{kN} / \mathrm{mm}$. On top of the steel bearings, there was a steel strip of $100 \mathrm{~mm} \times$ $15 \mathrm{~mm} \times 2500 \mathrm{~mm}$ and 7 strips of felt type $\mathrm{N} 100$ of $100 \mathrm{~mm} \times 5 \mathrm{~mm} \times 280 \mathrm{~mm}$. The properties of the felt have been tested [12].

Support 1 represents a simple support. Vertical prestressing bars couple the end of the slab to the laboratory floor (Fig. 2). Load cells measured the magnitude of the force in the prestressing bars. These bars restrain the rotation at support 2 , creating a moment over support 2 and thus simulating a continuous support (CS). The prestress was applied before the start of every test, initially compensating for the self-weight of the slab. Some rotation can occur at support 2. Lasers, placed on auxiliary frames over the supports and close to the loads, are used to measure the displacements. A complete description of the experiments and instrumentation is given in the full test report [13].

\subsection{Specimens}

An overview of the properties of the eight tested slabs $(5 \mathrm{~m} \times 2,5 \mathrm{~m} \times 0,3 \mathrm{~m})$ is given in Table 1 . The character $\mathrm{M}$ denotes loading

with the concentrated load in the middle of the slab width. S denotes loading with the concentrated load at the side at $438 \mathrm{~mm}$ from the free edge, Fig. 2 . Reinforcement S500 $\left(f_{y}=541 \mathrm{MPa} ; f_{u}=658\right.$ $\mathrm{MPa}$ ) was used [12]. The reinforcement layout of slabs S19-S26 was not varied and was kept the same as used in the first series of experiments to allow for comparison. The concrete cover was 25 $\mathrm{mm}$, resulting in an effective depth to the longitudinal reinforcement $d_{l}$ of $265 \mathrm{~mm}$. The amount of transverse flexural reinforcement $\rho_{t}$ is traditionally taken as 20\% of $\rho_{l}$ (EN 1992-1-1:2005 $\S 9.3 .1 .1 .(2)$ [2]). In the slabs, $25,9 \%$ of $\rho_{l}$ was used for the transverse reinforcement. Normal strength concrete $\mathrm{C} 28 / 35$ was used for all specimens. Glacial river aggregates with a maximum aggregate size of $16 \mathrm{~mm}$ were used. The $200 \mathrm{~mm} \times 200 \mathrm{~mm}$ load was a 1:2 scale representation of the $400 \mathrm{~mm} \times 400 \mathrm{~mm}$ contact surface of each wheel of the axle load used in load model 1 of EN1991-2:2002 [2]. In Table 1, the following symbols are used:

$f_{c}$ ' the average cube compressive strength measured at the age of testing the slab

$f_{c t} \quad$ the average tensile splitting strength measured on cubes at the age of testing the slab

$\rho_{l} \quad$ the percentage of longitudinal reinforcement of the specimen

$\rho_{t} \quad$ the percentage of transverse reinforcement of the specimen

$a$ the centre-to-centre distance between the load and the support

$d_{l} \quad$ the effective depth to the longitudinal reinforcement 
$a_{v} \quad$ the face-to-face distance between the load and the support

$z_{\text {load }} \quad$ the size of the side of the square loading plate; equals $b_{\text {load }}=l_{\text {load }}$

$\mathrm{M} / \mathrm{S} \quad$ loading with the concentrated load in the middle (M) or near the edge (S) of the width

age the age of the concrete slab specimen at testing.

Table 1: Properties of slabs S19-S26.

\begin{tabular}{cccccccccc}
\hline $\begin{array}{c}\text { Slab } \\
\text { nr. }\end{array}$ & $\begin{array}{c}f_{c}{ }^{\prime} \\
(\mathrm{MPa})\end{array}$ & $\begin{array}{c}f_{c t} \\
(\mathrm{MPa})\end{array}$ & $\begin{array}{c}\rho_{l} \\
(\%)\end{array}$ & $\begin{array}{c}\rho_{t} \\
(\%)\end{array}$ & $a / d_{l}$ & $a_{v} / d_{l}$ & $\begin{array}{c}z_{\text {load }} \\
(\mathrm{mm})\end{array}$ & $\mathrm{M} / \mathrm{S}$ & $\begin{array}{c}\text { age } \\
\text { (days) }\end{array}$ \\
\hline S19 & 56,92 & 4,67 & 0,996 & 0,258 & 2,26 & 1,17 & 300 & $\mathrm{M}$ & 89 \\
S20 & 60,51 & 4,67 & 0,996 & 0,258 & 2,26 & $1,17 / 1,36$ & var & $\mathrm{M}$ & 176 \\
S21 & 56,76 & 4,48 & 0,996 & 0,258 & 2,26 & 1,51 & 300 & $\mathrm{M}$ & 187 \\
S22 & 57,97 & 4,48 & 0,996 & 0,258 & 2,26 & 1,51 & 300 & $\mathrm{~S}$ & 188 \\
S23 & 58,87 & 4,65 & 0,996 & 0,258 & 2,26 & 1,51 & 300 & $\mathrm{M}$ & 197 \\
S24 & 58,87 & 4,65 & 0,996 & 0,258 & 2,26 & 1,51 & 300 & $\mathrm{~S}$ & 183 \\
S25 & 58,57 & 4,47 & 0,996 & 0,258 & $2,26 / 1,51$ & $1,51 / 0,755$ & 300 & $\mathrm{M}$ & 170 \\
S26 & 58,57 & 4,47 & 0,996 & 0,258 & 1,51 & 0,755 & 300 & $\mathrm{M} \& \mathrm{~S}$ & 174 \\
\hline
\end{tabular}

\section{Results and discussion}

\subsection{Test results}

The results of the experiments are given in Table 2, in which the following symbols are used:

$b_{r} \quad$ distance between the edge and the centre of the concentrate load

$\mathrm{SS} / \mathrm{CS} \quad$ loading near the simple or the continuous support. In the cases of the additional

experiments in which the prestressing was removed, and the slab was rotated by $180^{\circ}$, the side is denoted as SS'

uncr/c testing on specimen without existing cracks ("uncr") or in the vicinity of a local failure ("c"). If the result of an experiment close to a local failure caused by a previous test can be used for the analysis "c, OK" is written in Table 1.

$P_{u} \quad$ the force on the concentrated load at failure

$P_{\text {line }} \quad$ the force on the jack of the line load, which was distributed over $2,5 \mathrm{~m}$.

Mode the observed failure mode: failure as a wide beam in shear with inclined cracks on the bottom of the specimen (WB); failure as a beam in shear with a noticeable shear crack at the side (B); beam shear failure away from the support, typically between the concentrated load and the line load (B') or development of a partial punching surface on the bottom face $(\mathrm{P})$

$F_{\text {pres }} \quad$ the sum of the forces on the three prestressing bars creating a moment over support 2

$V_{\max } \quad$ the resulting maximum shear force at the support, taking into account the concentrated load, line load, self-weight of the slab, self-weight of the line load (HEM 1000 profile) and the force due to the prestressing bars.

Table 2: Results of second series of experiments

\begin{tabular}{lccccccccc}
\hline Test & $a / d$ & $\begin{array}{c}b_{r} \\
(\mathrm{~mm})\end{array}$ & SS/CS & uncr/c & $\begin{array}{c}P_{u} \\
(\mathrm{kN})\end{array}$ & $\begin{array}{c}P_{\text {line }} \\
(\mathrm{kN})\end{array}$ & Mode & $\begin{array}{c}F_{\text {pres }} \\
(\mathrm{kN})\end{array}$ & $\begin{array}{c}V_{\max } \\
(\mathrm{kN})\end{array}$ \\
\hline S19T2 & 2,26 & 1250 & SS & uncr & 1484 & 0 & $\mathrm{WB}$ & 112 & 1249 \\
S19T1 & 2,26 & 1250 & $\mathrm{CS}$ & uncr & 1568 & 0 & $\mathrm{WB}$ & 217 & 1379 \\
\hline S20T1 & 2,26 & 1250 & SS & uncr & 1542 & 603 & $\mathrm{~B}$ & 870 & 1579 \\
S20T2 & 2,26 & 1250 & $\mathrm{CS}$ & $\mathrm{c}$ & 1273 & 602 & $\mathrm{~B}$ & 1408 & 1739 \\
S20T2b & 2,26 & 1250 & $\mathrm{CS}$ & uncr & 1552 & 601 & $\mathrm{WB}$ & 678 & 1657 \\
S20T3 & 2,26 & 438 & $\mathrm{CS}$ & uncr & 1337 & 601 & $\mathrm{WB}+\mathrm{B}$ & 643 & 1487 \\
S20T4 & 2,26 & 438 & $\mathrm{CS}$ & uncr & 1449 & 601 & $\mathrm{WB}+\mathrm{B}$ & 637 & 1569 \\
\hline S21T1 & 2,26 & 1250 & $\mathrm{CS}$ & uncr & 1165 & 602 & $\mathrm{WB}+\mathrm{B}+\mathrm{B}$ & 343 & 1472
\end{tabular}




\begin{tabular}{lccccccccc} 
S21T2 & 2,26 & 1250 & SS & uncr & 1386 & 603 & WB + B' & 297 & 1544 \\
S21T3 & 5,25 & 438 & SS' & c & 730 & 0 & B & 0 & 479 \\
S21T4 & 5,25 & 438 & SS' & c & 753 & 0 & B & 0 & 493 \\
S21T5 & 3,28 & 438 & SS' & c, OK & 853 & 0 & WB + B + B' & 0 & 678 \\
S21T6 & 4,26 & 438 & SS' & c & 785 & 0 & B' & 0 & 569 \\
\hline S22T1 & 2,26 & 438 & CS & uncr & 984 & 602 & WB + B & 335 & 1320 \\
S22T2 & 2,26 & 438 & CS & uncr & 961 & 602 & WB + B & 323 & 1298 \\
S22T3 & 2,26 & 438 & SS & uncr & 978 & 603 & WB + B & 195 & 1221 \\
S22T4 & 2,26 & 438 & SS & uncr & 895 & 604 & WB + B & 252 & 1143 \\
\hline S23T1 & 2,26 & 1250 & CS & uncr & 1386 & 601 & WB + B + B' & 332 & 1653 \\
S23T2 & 2,26 & 1250 & SS & uncr & 1132 & 602 & WB + B & 230 & 1343 \\
\hline S24T1 & 2,26 & 438 & CS & uncr & 1358 & 601 & WB + B' & 327 & 1629 \\
S24T2 & 2,26 & 438 & CS & uncr & 1182 & 601 & WB + B & 295 & 1477 \\
S24T3 & 2,26 & 438 & SS & uncr & 995 & 602 & WB + B' & 190 & 1235 \\
S24T4 & 2,26 & 438 & SS & uncr & 784 & 602 & WB + B & 262 & 1048 \\
\hline S25T1 & 2,26 & 1250 & SS & uncr & 1461 & 0 & WB + P & 203 & 1214 \\
S25T2 & 1,51 & 1250 & CS & uncr & 1620 & 601 & WB + B & 372 & 1945 \\
S25T3 & 1,51 & 438 & CS & c & 1563 & 602 & WB + B & 358 & 1893 \\
S25T4 & 3,28 & 438 & SS & c, OK & 854 & 0 & WB + B & 0 & 678 \\
S25T5 & 4,26 & 438 & SS & c, OK & 968 & 0 & WB + B & 0 & 695 \\
\hline S26T1 & 1,51 & 438 & SS & uncr & 1448 & 602 & WB + B' & 187 & 1686 \\
S26T2 & 1,51 & 438 & SS & uncr & 1324 & 602 & B & 238 & 1568 \\
S26T3 & 1,51 & 1250 & CS & uncr & 1555 & 602 & WB + B & 418 & 1896 \\
S26T4 & 1,51 & 438 & CS & c & 1363 & 602 & B & 418 & 1725 \\
S26T5 & 1,51 & 438 & CS & c & 1451 & 602 & WB + B & 422 & 1804 \\
\hline
\end{tabular}

\subsection{Hypothesis of superposition}

To verify the hypothesis of superposition, the failure shear stress at the support from the seconds

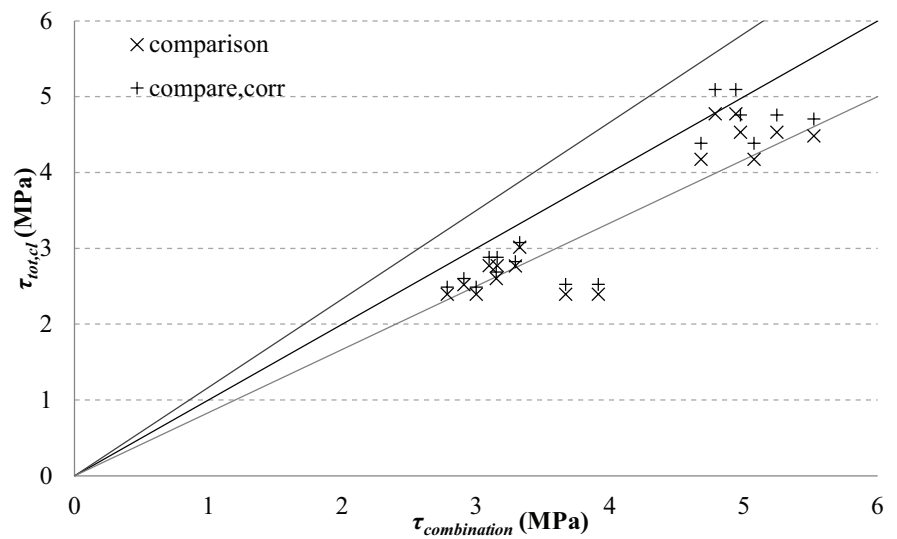

of superposition, also indicating bandwidth of scatter on material properties series of tests is compared to the failure shear stress in a similar experiment from the first series. If the principle of superposition holds true, then the shear stress (calculated over $b_{\text {eff }}$ ) of the experiment with a concentrated load only, $\tau_{\text {tot, }, \text { }}$, should be similar to the sum of the shear stress due to the loads which act over the full width $b$ (line load, dead load and vertical prestressing load), $\tau_{\text {line }}$, with the shear stress due to the concentrated load acting over $b_{\text {eff, }} \tau_{\text {conc. }}$. In Fig. 3 , the results of the experiments with a combination of loads $\left(\tau_{\text {combination }}=\tau_{\text {line }}\right.$ $+\tau_{\text {conc }}$ ) are compared to the results of a similar experiment with a concentrated

load only. There is a difference in the cube compressive strengths of the concrete used in the experiments with multiple loads and the experiments with a concentrated load only. Although all specimens were made with a concrete $\mathrm{C} 28 / 35$, the age of testing was not the same. Therefore, a correction has been made by multiplying $\tau_{\text {tot, }, ~}$ with the cube root (as used in EN 1992-1-1:2005 [2]) of the ratio between the compressive strength of the specimen loaded with a concentrated load only

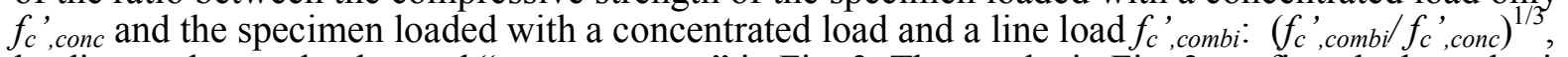
leading to the results denoted "compare, corr" in Fig. 3. The results in Fig. 3 confirm the hypothesis of superposition of a reduced concentrated load distributed over an effective width with a line load. 
Typically, higher shear stresses can be attained when combining different loads. When considering 36 cubes tested in compression at an age of 28 days for C28/35 concrete, a standard deviation of $3,68 \mathrm{MPa}$ and a coefficient of variation of $8,5 \%$ is found. The scatter on the experimental results, with 2 cases of slabs under a combination of loads resulting in a lower shear capacity than for a slab under a concentrated load only, lies within the bandwidth resulting from the scatter of the material properties.

\subsection{Moment distribution at the support}

All specimens were tested near the simple support (sup 1 in Fig. 2) and near the continuous support (sup 2 in Fig. 2). As the force on the prestressing bars was only applied at the start of every experiment, the resulting moment at the continuous support was on average $38 \%$ of the moment in a fully fixed support for the slabs with an initial force on the prestressing bars of $3 \times 15 \mathrm{kN}$ and $52 \%$ of the moment in a fully fixed support for the slabs with an initial force on the prestressing bars of 3 $\times 50 \mathrm{kN}$. The results of the experiments [14] show that slabs under a combination of loads have on average a $16 \%$ larger shear capacity at the continuous support than at the simple support. The load cells at the support are used to measure the reaction force distribution. If the effective width is determined from this force profile, it is found that the effective width at the continuous support is smaller than the effective width at the simple support.

To take into account the moment distribution at the continuous support, the shear capacity at the continuous support can be increased with a factor[15]:

$$
\alpha=\sqrt{\frac{M_{1}+M_{2}}{M_{1}}}
$$

in which $M_{1}$ is the largest moment in the shear span, $a$, (distance between the load and the support) and $M_{2}$ the smallest. In this case of combined loads, the largest moment $M_{1}$ is at the location of the concentrated load and the smallest is taken at the support $M_{2}$.

Table 3: Comparison between experimental results and shear capacities according to EN 1992-11:2005 [2] at simple and continuous support.

\begin{tabular}{lccc}
\hline & $\tau_{\text {test }} / v_{\text {Rd,c }}$ & $\tau_{\text {test }} / \nu_{\text {Rd,c }}$ & $\tau_{\text {test }} / \alpha v_{\text {Rd,c }}$ \\
& $\mathrm{SS}$ & $\mathrm{CS}$ & $\mathrm{CS}$ \\
\hline AVG & 1,783 & 2,062 & 1,723 \\
STD & 0,242 & 0,176 & 0,163 \\
COV & 0,136 & 0,085 & 0,094 \\
\hline
\end{tabular}

The results of the comparison between the maximum shear stress at the support in the experiment, $\tau_{\text {test }}$, and the shear capacity predicted by EN 1992-1-1:2005 [2], $v_{R d, c}$, is shown in Table 3. The influence of applying the enhancement factor $\alpha$ to the shear capacity is shown as $\alpha v_{R d, c}$. The results in Table 3 show that applying the enhancement factor $\alpha$ is a good solution to regard the increased shear capacity at the continuous support: the average value of the ratio between the experimental shear stress at the support and the shear capacity is now almost the same for the experiments at the simple support as compared to the experiments at the continuous support.

\subsection{Flexible versus rigid supports}

Slabs S24 and S25 are supported on flexible supports. It should be noted that the same centre-tocentre distance $a$ between the load and the support was used for these experiments, but that the support width was different, leading to a different face-to-face distance $a_{v}$ (Table 1). When comparing the failure shear stress at the support, similar shear capacities are found for the slabs on flexible supports as for the slabs on rigid supports. The difference in the experiments is that it was observed in that slabs on elastomeric supports show a more ductile failure mode than slabs on steel bearings. This observation is reflected in the load-displacement diagrams (Fig. 4). Also, based on the measurements of the reaction forces in the load cells at the support, it is found that the effective width is larger in the case of a support line of steel bearings than for elastomeric bearings. This observation corresponds to the expectations: a line of elastomeric bearings provides a less uniform surface than a line of steel bearings. Therefore, in a line of elastomeric bearings, more load is distributed towards the stiffer parts of the support line. The result is a higher peak value and thus a smaller effective width. 


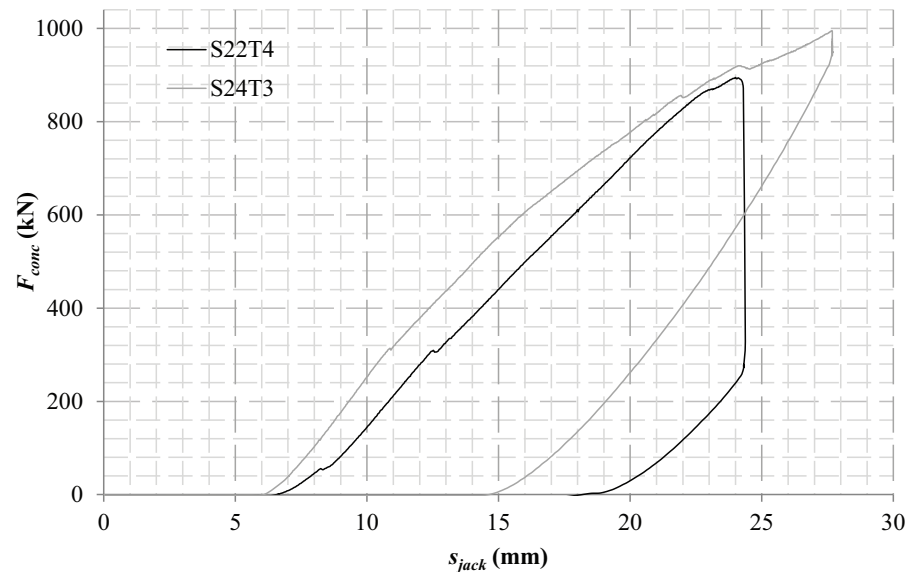

Fig. 4: : Load-displacement diagram of the jack in S22T4 (steel bearings) compared to S24T3 (elastomeric bearings).
EN 1992-1-1:2005 [2] allows for a reduction in the contribution of loads close to the support by virtue of direct load transfer with a factor $\beta=a_{v} / 2 d_{l}$ for $0,5 d_{l} \leq a_{v} \leq 2,5 d_{l}$. For rigid supports, the distance $a_{v}$ is the clear shear span, which is the face-to-face distance between the load and the support. For flexible supports, the distance $a_{v}$ needs to be taken to the centre of the support according to EN 1992-1-1:2005 [2]. However, the results of the experiments do not support this code requirement, and more uniform results are obtained when for the slabs on flexible support, the distance $a_{v}$ is taken to the face of the support. Therefore, it is advised to use the clear shear span $a_{v}$ to determine the factor $\beta$ for all supports.

\section{Summary and Conclusions}

In a first series of experiments of slabs under a concentrated load close to the support, it was found that transverse load redistribution results in higher shear capacities for slabs under concentrated loads near to the support. In the second series of experiments, slabs were tested under a combination of loads: a line load to represent the distributed loads and a concentrated load to represent the wheel loads. The resulting ratio of the contribution of the concentrated load and the contribution of the distributed loads to the shear stress at the support is representative for existing slab bridges under dead load, superimposed loads and live loads. The goal of the second series of experiments is to study the hypothesis of superposition. If this hypothesis holds true, the contribution of the concentrated loads can be distributed over their effective widths and the contribution of the distributed loads over the entire slab width. For this purpose, 33 experiments on 8 specimens have been carried out. The following conclusions follow from the experiments:

- Assuming superposition of the contribution of the concentrated load over the effective width and the distributed load over the full width results in conservative results when compared to the experimental results of the failure shear stress in a slab under a concentrated load only.

- The shear capacity at the continuous support is measured to be $16 \%$ higher than at the simple support. The effective width from the distribution profile of the reaction forces is smaller at the continuous support than at the simple support.

- The additional capacity at the continuous support can be taken into account by using the enhancement factor $\alpha$ for the moment distribution in the shear span to the shear capacity from EN 1992-1-1:2005.

- In slabs on flexible supports, a more ductile failure mechanism is observed and shear cracks are visible before reaching the failure load.

- The experiments do not support the provision from EN 1992-1-1:2005 that for slabs on flexible supports the reduction of the contribution of loads near to the support to the resulting shear force at the support should be based on the distance between the face of the load and the centre of the support.

\section{Acknowledgements}

The authors wish to express their gratitude and sincere appreciation to the Dutch Ministry of Infrastructure and the Environment (Rijkswaterstaat) for financing this research work.

\section{References}

[1] CEN, Eurocode 1-Actions on Structures - Part 2: Traffic loads on bridges, EN 1991-2. Comité Européen de Normalisation, Brussels, 2003, p. 168 
[2] CEN, Eurocode 2-Design of Concrete Structures: Part 1-1 General Rules and Rules for Buildings, EN 1992-1-1. Comité Européen de Normalisation, Brussels, 2005, p. 229.

[3] NORMCOMISSIE 351001, NEN 6720 Technische Grondslagen voor Bouwvoorschriften, Voorschriften Beton TGB 1990 - Constructieve Eisen en Rekenmethoden (VBC 1995), Civieltechnisch centrum uitvoering research en regelgeving, Nederlands Normalisatieinstituut, Delft, 1995, p. 245.

[4] LUBELL, A. S., BENTZ, E. C., and COLLINS, M. P., "Influence of Longitudinal Reinforcement on One-Way Shear in Slabs and Wide Beams." ASCE Journal of Structural Engineering, Vol. 135, No. 1, 2009, pp. 78-87.

[5] SHERWOOD, E. G., LUBELL, A. S., BENTZ, E. C., and COLLINS, M. P., "One-way shear strength of thick slabs and wide beams." ACI Structural Journal, Vol. 103, No. 6, 2006, pp. 794-802.

[6] LANTSOGHT, E. O. L., VAN DER VEEN, C., and WALRAVEN, J. C., "Shear capacity of slabs and slab strips loaded close to the support." ACI SP-287, Recent Development in Reinforced Concrete Slab Analysis, Design and Serviceability, 2012, pp. 5.1-5.18.

[7] LANTSOGHT, E.O.L., VAN DER VEEN, C., and WALRAVEN, J. " Shear Assessment of Reinforced Concrete Slab Bridges" IABSE 2013, Rotterdam, 2013.

[8] LANTSOGHT, E.O.L, Voortgangsrapportage: Experimenten op platen in gewapend beton: Deel II: analyse van de resultaten, Delft University of Technology, 2012, p. 289.

[9] LANTSOGHT, E.O.L., Shear in reinforced concrete slabs under concentrated loads close to the support - Literature review, Delft University of Technology, 2012, p. 265.

[10] REIßEN, K., and HEGGER, J. "Shear Capacity of Reinforced Concrete Slabs under Concentrated Loads." IABSE 2012, Korea, pp. 8.

[11] ROMBACH, G., and LATTE, S. "Querkrafttragfahigkeit von Fahrbahnplatten ohne Querkraftbewehrung." Beton- und Stahlbetonbau, Vol. 104, No. 10, 2009, pp. 642-656.

[12] PROCHAZKOVA, Z., and LANTSOGHT, E.O.L., Material properties - Felt and Reinforcement For Shear test of Reinforced Concrete Slab. Delft University of Technology, 2011, pp. 28.

[13] LANTSOGHT, E.O.L., Tests of reinforced concrete slabs subjected to a line load and a concentrated load, Delft University of Technology, 2012, pp. 268.

[14] LANTSOGHT, E.O.L., Voortgangsrapportage: Experimenten op platen in gewapend beton onder combinatiebelasting: Deel II: analyse van de resultaten, Delft University of Technology, 2012, p. 98.

[15] REGAN, P. E., Shear Resistance of Concrete Slabs at Concentrated Loads close to Supports. Polytechnic of Central London, 1982, pp. 24. 